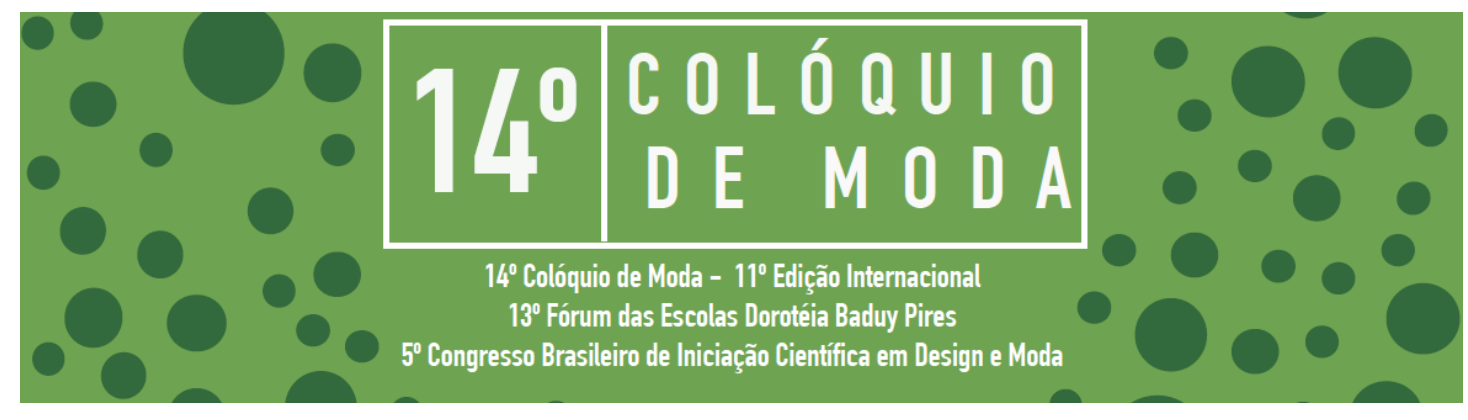

\title{
SUSTENTABILIDADE NO COLÓQUIO DE MODA: MAPEAMENTO E CATEGORIZAÇÃO DE ARTIGOS
}

Sustainability on Colóquio de Moda: papers mapping and categorization

Puppim, Régis; Doutorando; Universidade do Minho/Portugal e Instituto Federal de Goiás (IFG), regispuppim@gmail.com ${ }^{1}$

Mendes, Luisa Arruda; Doutoranda; Universidade do Minho/Portugal, luisamendesarruda@gmail.com ${ }^{2}$

Broega, Ana Cristina; Doutora; Universidade do Minho/Portugal, cbroega@det.uminho.pt ${ }^{3}$

\section{Resumo}

Esta pesquisa avalia os artigos sobre Sustentabilidade no Colóquio de Moda (20052017), usando a metodologia de mapeamento, em estudo quantitativo e qualitativo. Nesta proposta, analisa-se, numericamente, a ocorrência deste tema como pauta dos artigos, e ainda a incidência dos artigos em uma sugestão de categorização: MatériaPrima, Processos, Consumo, Fim de Ciclo de Vida do produto e Transparência.

Palavras chave: Moda e Sustentabilidade; Categorias da Moda e Sustentabilidade; Colóquio de Moda.

\section{Abstract}

This research evaluates the papers on Sustainability of the Colóquio de Moda (20052017), using mapping methodology, in a quantitative and qualitative study. On this proposal, it is analyzed, numerically, the occurrence of this field as theme for papers

\footnotetext{
${ }^{1}$ Bacharel em Design de Moda (UFG), Especialista em Design Estratégico (Istituto Europeo di Design), Mestre em Arte e Cultura Visual (UFG) e Doutorando em Engenharia Têxtil (UMINHO/PT). Professor de Educação Básica, Técnica e Tecnológica do Instituto Federal de Goiás (IFG), Campus Aparecida de Goiânia, licenciado para período de estudos de Doutorado. ${ }^{2}$ Tecnóloga em Design de Moda (UVV), Mestra em Artes (UFES) e Doutorando em Engenharia Têxtil (UMINHO/PT). Pesquisadora do Centro de Ciência e Tecnologia Têxtil (2C2T) da Universidade do Minho.

${ }^{3}$ Doutora em Engenharia Têxtil e Professora da Universidade do Minho (UMINHO/PT).
}

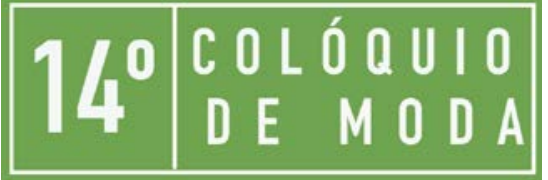

\section{abepem}




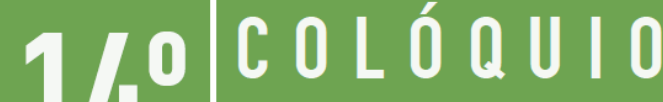 DE MODA \\ $14^{\circ}$ Colóquio de Moda - $11^{\circ}$ Ediçãa Internacional \\ $13^{0}$ Fórum das Escolas Dorotéia Baduy Pires \\ $5^{0}$ Congresso Brasileiro de Iniciação Cientifica em Design e Moda}

and the incidence of papers in a categorization suggestion: Raw Materials, Processes, Consumption, Product end of life cycle and Suitability.

Keywords: Fashion and Sustainability; Fashion and Sustainability Categories; Colóquio de Moda.

\section{Introdução}

O Colóquio de Moda, que em 2018 realiza sua 14ª edição, é considerado, acadêmica e cientificamente, um congresso de pesquisa na área de Moda de grande participação dos estudantes e investigadores e com alto nível de impacto de discussões e reflexões críticas sobre o tema e seus desdobramentos.

O objetivo do evento, surgido em 2005, é de estimular a disseminação do conhecimento científico de Moda, impulsionando o debate acadêmico entre estudantes de graduação e pós-graduação, bem como de pesquisadores e docentes (CASTILHO e MATTOS, 2015). As possíveis subáreas de investigação da Moda são contempladas, no evento, com Grupos de Trabalhos (GTs) que exibem apresentações orais e pôsteres de artigos científicos. Surgido de uma necessidade emergente de reflexões anteriores, o GT de Moda e Sustentabilidade foi estabelecido em 2009, na $5^{a}$ edição, ocorrida em Recife/PE (MIRANDA, 2015).

A necessidade de debate da temática "Moda e Sustentabilidade" aparecera, mesmo em edições anteriores, e o volume de produções no GT teve significativo crescimento desde sua inauguração. Portanto, este artigo tem como objetivo mapear as publicações (Comunicações Orais - Artigos) de Moda e Sustentabilidade no âmbito do Colóquio de Moda, em todas suas edições com anais já publicados (2005-2017), e propõe, ainda, agrupamentos de temáticas constantes nos artigos, como modo de categorização.

Metodologicamente, trata-se de um estudo quantitativo e qualitativo, sendo o mapeamento a ferramenta metodológica selecionada para tal. As análises foram 


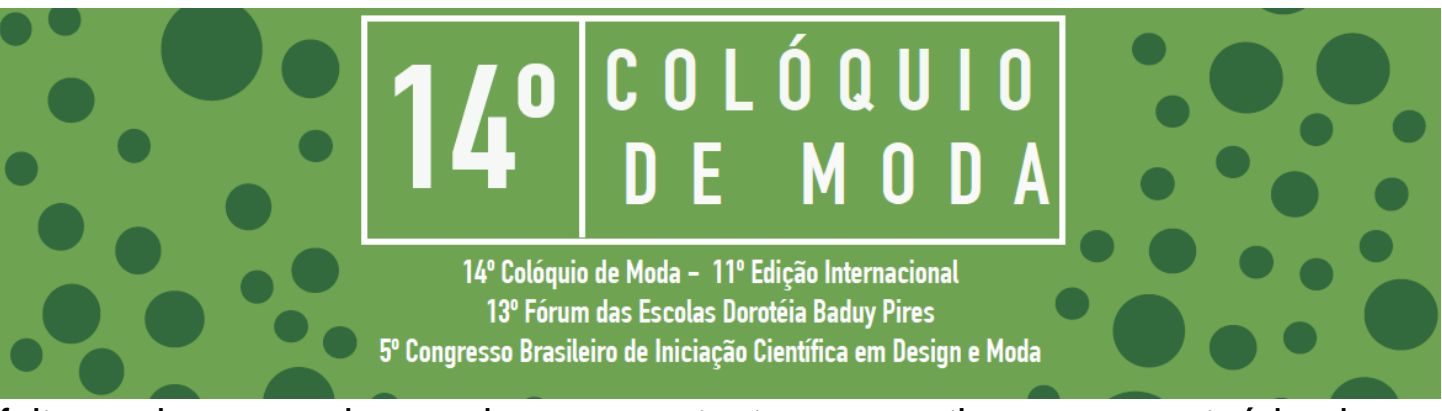

feitas sobre as palavras-chaves constantes nos artigos e o conteúdo de seus resumos, como modo de, inicialmente, demonstrar numericamente o volume de produção, e, posteriormente, subdividir em categorias comum às temáticas abordadas. Na busca de palavras-chaves utilizou-se os termos "Sustentável", "Sustentabilidade", "Eco", "Ecológico", "Ecologicamente correto", "Meio Ambiente", "Ambiental" e "Ético". Como premissa para esta investigação, utilizou-se os dados coletados por Silva e Giuliano (2017), que realizaram estudo bibliométrico sobre Moda e Sustentabilidade no Colóquio de Moda.

\section{Sobre Sustentabilidade}

Inicialmente ao explorar a leitura de autores que discorrem sobre Sustentabilidade, como grande área, torna-se necessário perceber as engrenagens e pormenores da temática, de recente popularização. Neste sentido, revisita-se renomados autores deste segmento (VEIGA, 2010; BOFF, 2012; SACHS, 2009).

Em Sachs (2009), considerado por muitos estudiosos um dos grandes baluartes dos estudos sobre Sustentabilidade, apresenta-se, sobretudo, os critérios para o desenvolvimento sustentável, em especial o Social, o Cultural, o Ecológico, o Ambiental e o Econômico, ensejando o caráter de Ciências Sociais da Sustentabilidade. Enquanto em Veiga (2010), analisa-se a emergência e consolidação do termo puro "Sustentabilidade" e instiga-se a refletir sobre a real aplicabilidade dele, empunhando a perspectiva da Economia à Sustentabilidade. Por fim, em Boff (2012), racionaliza-se críticas as maneiras como se é naturalizado ao mundo e às práticas "insustentáveis", particularmente, enfocado no desenvolvimento, na educação e, ainda, no indivíduo, revelando a Sustentabilidade sob a ótica da Filosofia.
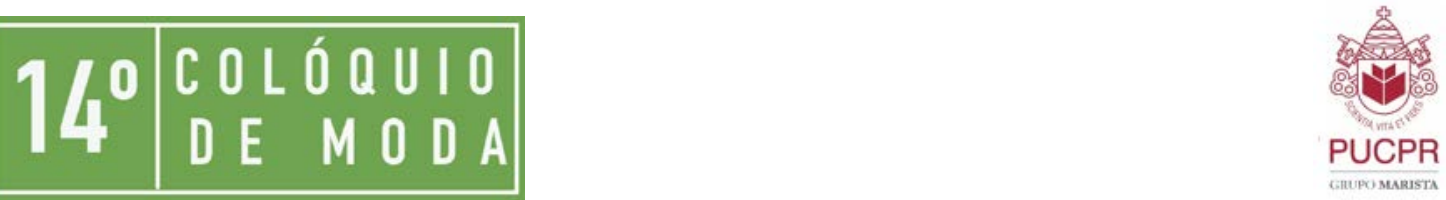

\section{abepem}




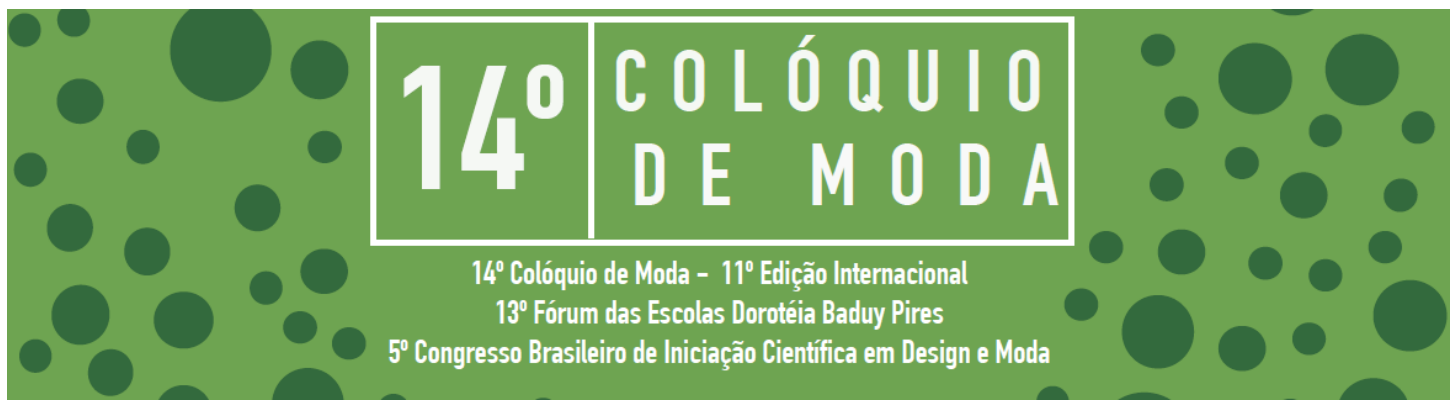

Mensura-se, ainda, a dialógica de Sustentabilidade com o Design (grande área de estudo onde se pode enquadrar a Moda), intermediando a trajetória até a convergência com a Moda. Neste égide, elege-se recapitular Manzini e Vezzoli (2011), autores pioneiros e consagrados desta tônica, e introduz-se à Queiroz (2014), com escopo essencialmente crítico trazido à Sustentabilidade no Design. Os primeiros abordam uma introdução às possibilidades de tornar os produtos industriais (e, por consequência, o Design) sustentáveis, focalizando no trabalho desenvolvido pelo Designer, em que se salienta aqui, o referencial (como o meio ambiente, a sociedade e as políticas), o projeto em si (e seu desenvolvimento) e possíveis instrumentos para avaliar a eficácia do que se propôs e/ou desenvolveu. Já a segunda autora, pelo perfil voltado à teoria crítica do Design, vislumbra padrões rigorosos para se efetivar a sustentabilidade no Design, considerando uma "utopia" a conjugação de "Design Sustentável", nomeando "transgressões" às miscelâneas que ocorrem entre a conexão dos termos (Sustentabilidade e Design).

Muito do que a referida autora aborda vai de encontro com o paradoxo incongruente (ou intentona) de se criar um substantivo adjetivado, seja ele "Moda Sustentável" ou "Design Sustentável". Outro aspecto que se ressalta e causa incômodo intelectual é uma contestação (aparentemente) óbvia: ao não seguir todos os aspectos/critérios de sustentabilidade, um produto/projeto não deve qualificar-se como "sustentável", por essência. E ainda, que produtos/projetos que sejam "sustentáveis" apenas sob um aspecto não contribuem, de nenhuma maneira, à Sustentabilidade.

Ao ser tão contundente, a autora confronta-se, em discurso, aos demais autores de Sustentabilidade. Em especial, Boff (2012), advertindo que, mesmo as pequenas ações, em prol de um resultado mais sustentável que o comum, traz 


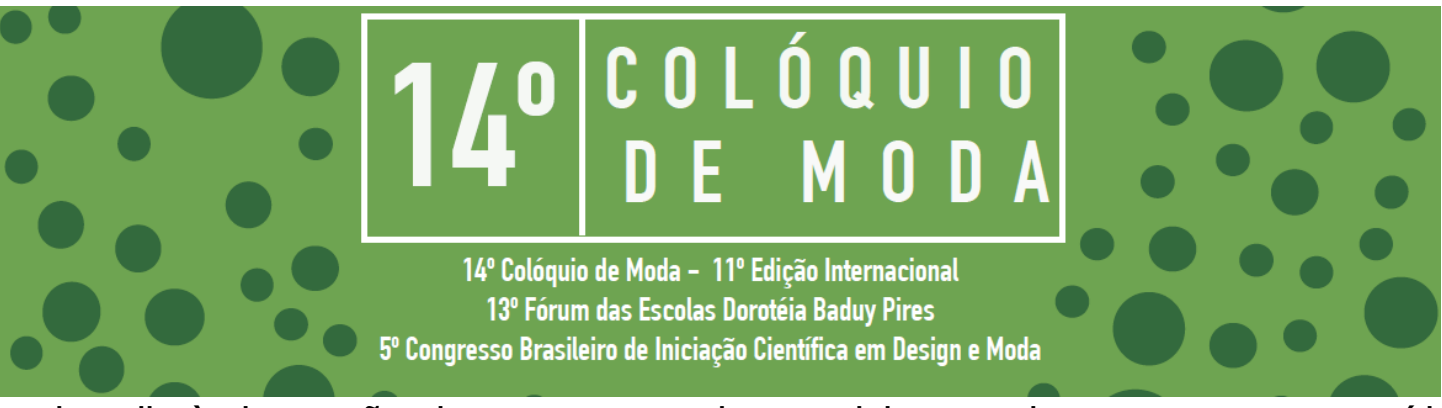

mais valia às interações humanas e ao desenvolvimento de um pensamento crítico à sustentabilidade, mesmo que no cotidiano. Pois o autor crê que não se pode exigir que grandes mudanças ocorram em curto período de tempo.

Neste enfrentamento, contempla-se e padece-se mais da visão de Boff que a de Queiroz, onde se é levado a um nível superior de criticidade, assimilando as propostas daquela como potencial objeto de análise e averiguação desta pesquisa, mas não julgando implacavelmente propostas (em artigos, por exemplo) de outros autores, como poderia ser feito.

\section{Sobre Moda e Sustentabilidade - (Uma possível) Categorização}

Perpassadas as questões teóricas e fundamentadoras, sobre as Sustentabilidade e suas possíveis conexões e rizomas, pode-se adentrar ao conteúdo de autores que discorrem sobre Moda e Sustentabilidade. Ante as publicações que tratam sobre Moda e Sustentabilidade, a partir do critério de acessibilidade/alcançabilidade deste tipo de literatura e relevância em contribuições para a área, enquadram-se 9 autores (BROWN, 2010; BERLIM, 2012; LEE, 2009; FLETCHER, 2011; THOMPSON; THOMPSON, 2013; GWILT, 2014; SALCEDO, 2014; STYLES, 2014; SCHULTE, 2015).

Partindo de um estudo preliminar proposto por PUPPIM e BEDUSCHI (2018), os autores selecionados, mesmo que em visões distintas, por vezes, largamente distantes, apresentam nuances e perspectivas que podem ser tangentes em cinco aspectos, ou convergências, que ressaltam-se:

- Matéria-prima - que corresponde à perspectiva de materiais e insumos que compõem o vestuário, sendo têxteis ou não-têxteis; 


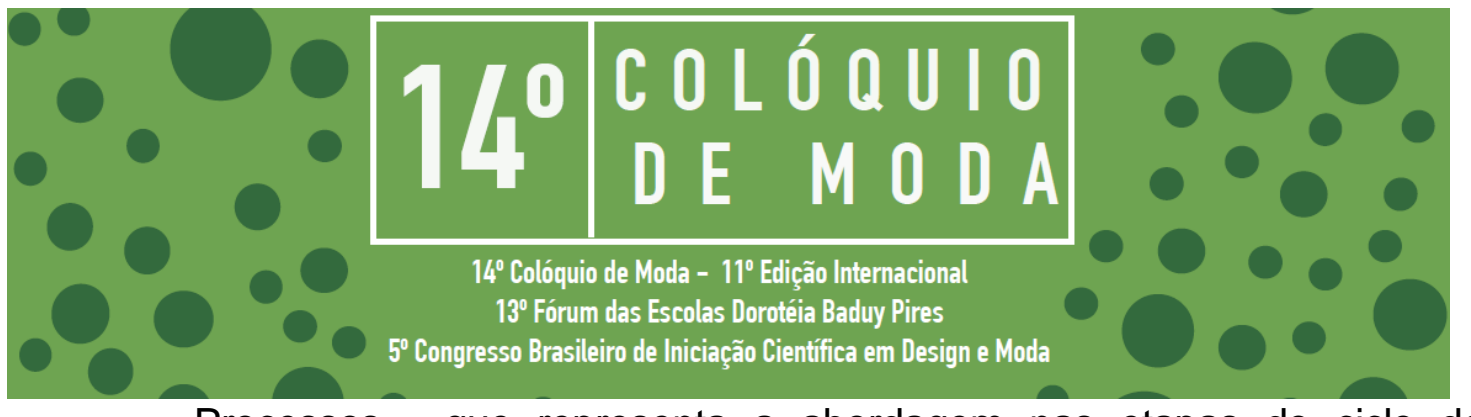

- Processos - que representa a abordagem nas etapas do ciclo de produção da indústria têxtil e do vestuário, como criação, modelagem, prototipagem, tingimento, costura ou mesmo outras montagens;

- Consumo - que refere-se à ótica do uso, da durabilidade e dos hábitos de compra dos usuários - no que tange à indumentária -, como análises da resistência de peças, frequência de novas aquisições, ou, mesmo, o entendimento do consumidor sobre a origem de seu produto;

- Final de ciclo de vida do produto - que diz respeito à seção do descarte de produtos e materiais, e as possibilidades de reuso, reutilização e reciclagem; e

- Transparência - que remete a selos e a certificações ambientais e de sustentabilidade, como avalistas da validação e idoneidade do adjetivo "sustentável" no vestuário e na indústria de confecção.

Deste modo, criou-se a Tabela 1, que ilustra, esquematicamente, a correspondência dos autores (com conceitos e/ou capítulos) que referenciam as categorias propostas.

Tabela 1: Correspondência de Conceitos - Autores e Categorias

\begin{tabular}{|c|c|c|c|c|c|}
\hline $\begin{array}{c}\text { Autor(es) } \\
\text { I Áreas }\end{array}$ & $\begin{array}{c}\text { Matéria- } \\
\text { Prima }\end{array}$ & Processos & Consumo & $\begin{array}{c}\text { Final de } \\
\text { ciclo de } \\
\text { vida }\end{array}$ & Transparência \\
\hline $\begin{array}{c}\text { Lee } \\
(\mathbf{2 0 0 9 )}\end{array}$ & $\begin{array}{c}\text { Capítulos } \\
\text { 3 e 6 }\end{array}$ & Capítulo 1 & Capítulo 10 & Capítulo 2 & $\begin{array}{c}\text { Capítulos 4, 7 } \\
\text { e 9 }\end{array}$ \\
\hline $\begin{array}{c}\text { Brown } \\
(\mathbf{2 0 1 0 )}\end{array}$ & "Slow Design" & $\begin{array}{c}\text { "Reuse" } \\
\text { "New Models" }\end{array}$ & $\begin{array}{c}\text { "Reuse, } \\
\text { Redesign \& } \\
\text { Recycle" }\end{array}$ & "Fair trade" \\
\hline $\begin{array}{c}\text { Fletcher } \\
\mathbf{( 2 0 1 1 )}\end{array}$ & $\begin{array}{c}\text { Cap. 1 - } \\
\text { Materiais }\end{array}$ & $\begin{array}{c}\text { Cap. 2 - } \\
\text { Processos }\end{array}$ & $\begin{array}{c}\text { Cap. 4- Cuidados } \\
\text { com o Consumidor/ } \\
\text { Cap. 7 - Vida útil } \\
\text { otimizada/ } \\
\text { Cap. 9-Serviços e } \\
\text { Compartilhamentos }\end{array}$ & $\begin{array}{c}\text { Cap. 5 - } \\
\text { Descarte }\end{array}$ & $\begin{array}{c}\text { Cap. 14 - } \\
\text { Engajamento }\end{array}$ \\
\hline
\end{tabular}




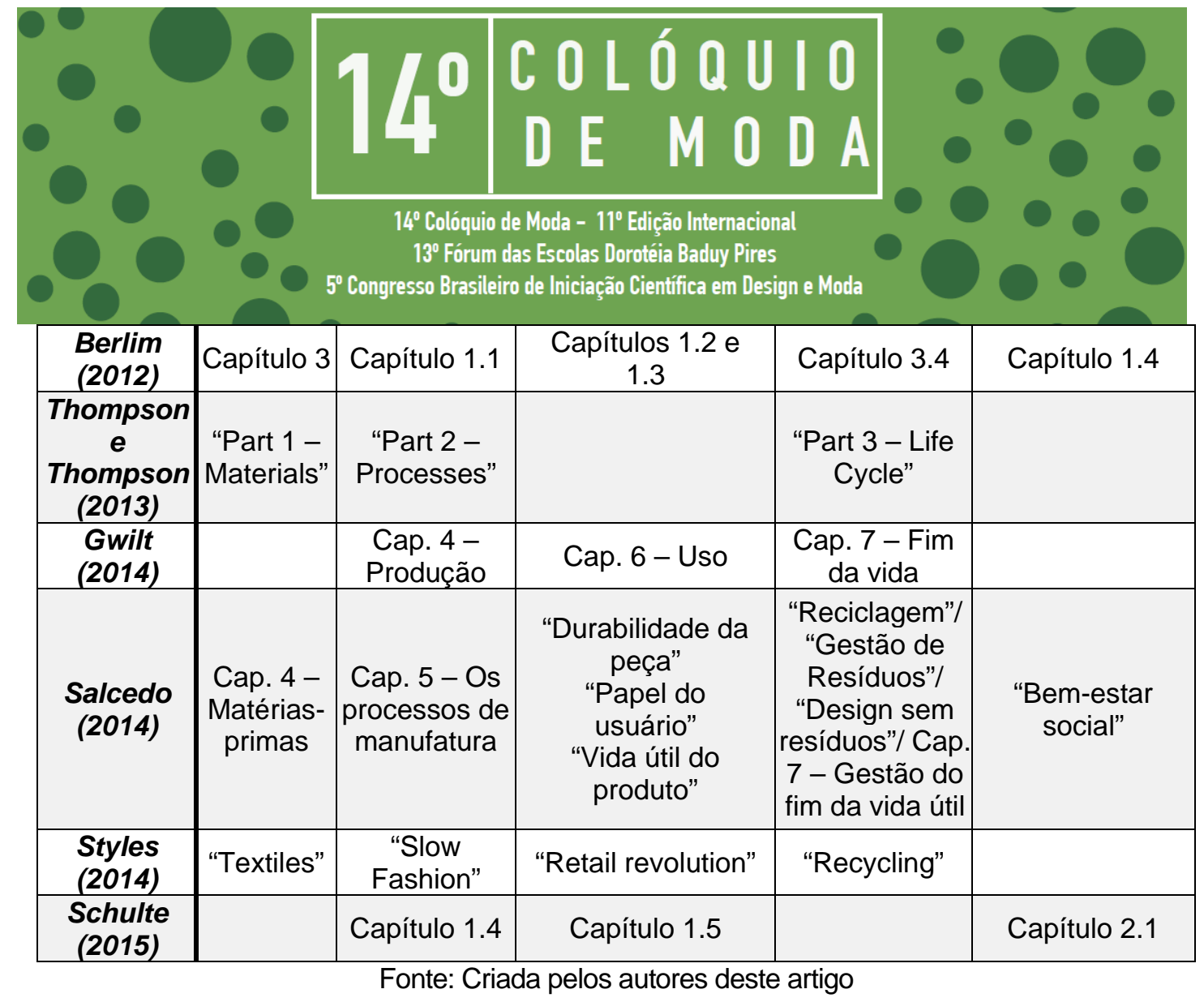

Outrossim, deduziu-se que a proposição de categorias para estudos em Moda e Sustentabilidade harmonizam-se com muitos dos conceitos e propostas de divisões dos autores levantados (os explícitos e, mesmo, outros não apresentados aqui). O quê, de fato, evidencia a eficácia e a eficiência das cinco sugestões, uma vez que ela é possível de ser replicada a outros estudos de Moda e Sustentabilidade.

Destaca-se, ainda, que, em geral, os autores tecem, ainda, subsídios às questões teóricas e críticas da Sustentabilidade na Moda, que não foi, aqui, apontado como categoria por se tratar de uma fundamentação teórica para investigações em Moda e Sustentabilidade. Outro aspecto relevante é que mesmo os autores que não adotam temáticas ou conceitos sobre um e outro item da proposta de categorias, formalmente, não deixam, de fato, de ao menos referenciar a valia, colaborando para a consolidação desta sugestão, aqui feita. 


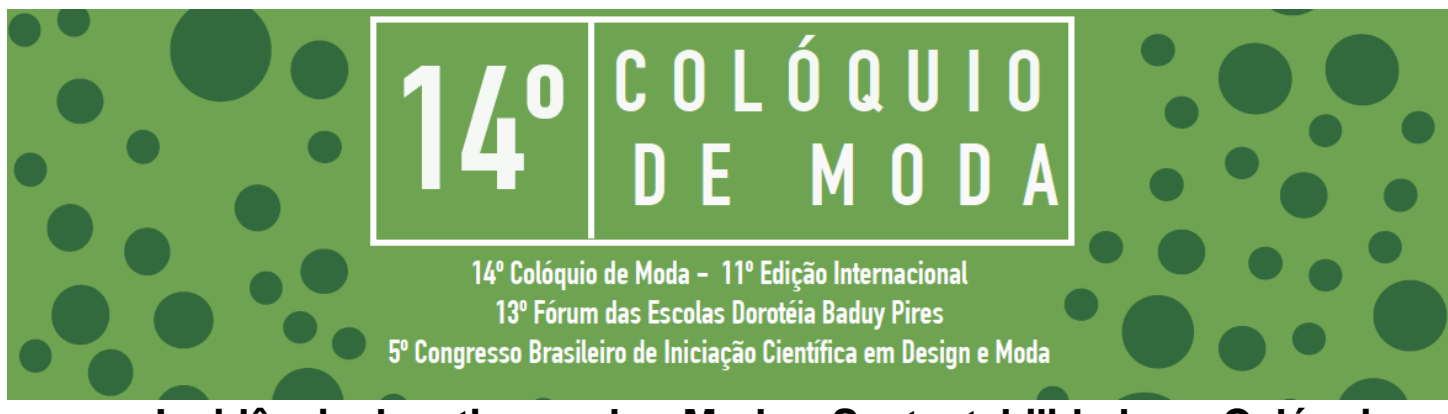

Incidência de artigos sobre Moda e Sustentabilidade no Colóquio

No que se refere à abordagem de Sustentabilidade na Moda, percebe-se que até os dias atuais, muitas empresas ainda estão no caminho de adaptação para este novo contexto (BROWN, 2010). Motivo pelo qual, ainda percebe-se uma alta aceitação de mercado de novas marcas, designers e projetos baseados nos valores sustentáveis. É notável, também, no Colóquio de Moda, a crescente dimensão dos artigos abordando sustentabilidade que majoritariamente, mas não só, se apresentam no GT Moda e Sustentabilidade, como visível na Tabela 2.

Tabela 2: Incidência de artigos sobre Sustentabilidade no Colóquio de Moda

\begin{tabular}{|c|c|c|c|}
\hline Edição Ano - Cidade & $\begin{array}{l}\text { Número Total } \\
\text { de Artigos em } \\
\text { GTs }\end{array}$ & \begin{tabular}{|c|} 
Número de \\
Artigos sobre \\
Sustentabilidade
\end{tabular} & $\begin{array}{c}\text { Percetual de } \\
\text { Artigos sobre } \\
\text { Sustentabilidade }\end{array}$ \\
\hline 2005 - Ribeirão Preto/SP & 64 & \begin{tabular}{|c|}
2 \\
\end{tabular} & $3,12 \%$ \\
\hline 2006 - Salvador/BA & 115 & 9 & $7,82 \%$ \\
\hline 2007 - Belo Horizonte/MG & 106 & 7 & $6,60 \%$ \\
\hline 2008 - Novo Hamburgo/RS & 146 & 15 & $10,27 \%$ \\
\hline 2009 - Recife/PE & 150 & 10 & $6,66 \%$ \\
\hline 2010 - São Paulo/SP & 289 & 9 & $3,11 \%$ \\
\hline 2011 - Maringá/PR & 188 & 15 & $7,97 \%$ \\
\hline 2012 - Rio de Janeiro/RJ & 236 & 38 & $16,10 \%$ \\
\hline 2013 - Fortaleza/CE & 228 & 38 & $16,66 \%$ \\
\hline 2014 - Caxias do Sul/RS & 164 & 30 & $18,29 \%$ \\
\hline 2015 - Curitiba/PR & 234 & 45 & $19,23 \%$ \\
\hline 2016 - João Pessoa/PB & 224 & 54 & $24,10 \%$ \\
\hline 2017 - Bauru/SP & 242 & 39 & $16,11 \%$ \\
\hline
\end{tabular}

Fonte: Criada pelos autores deste artigo, baseado nos anais dos Colóquios de Moda (2005-2017)

Apesar de não haver um crescimento contínuo, com variações positivas e negativas de percentuais, dos artigos que tratam sobre Sustentabilidade, deve-se 


\section{0/colóaulo DE MODA \\ $14^{\circ}$ Colóquio de Moda - $11^{\circ}$ Ediçãa Internacional \\ $13^{\circ}$ Fórum das Escolas Dorotéia Baduy Pires \\ $5^{0}$ Congresso Brasileiro de Iniciação Cientifica em Design e Moda}

ressaltar que no âmbito geral, já é estabelecido um patamar de, pelo menos, 16\% (ou 1 a cada 6, aproximadamente) há 6 edições - desde 2012 - revelando a consolidação da temática como agenda importante do evento. O ápice de participação fora em 2016, na $12^{a}$ edição do evento, ocorrida em João Pessoa/PB, representando quase 1 a cada 4 artigos apresentados.

A importância em se estabelecer um eixo temático que debate sobre a Sustentabilidade (e suas possibilidades) na Moda não é vista apenas do Colóquio de Moda, mas em diversos outros congressos nacionais e internacionais de Moda e Têxtil. Já existem grupos específicos de discussão (ou ao menos temática estabelecida) de Sustentabilidade em congressos como "Encontro Nacional de Pesquisa em Moda (ENPModa)", "Congresso Científico de Têxtil e Moda (CONTEXMOD)", "Congresso Internacional de Design e Moda (CIMODE)", "Textile Institute World Conference (TIWC)", "World Textile Conference (AUTEX)", "Aegean International Textile and Advanced Engineering Conference (AITAE)", entre outros.

Após o mapeamento, com ferramenta quantitativa, inicial, deve-se submeter a avaliação dos artigos sob a proposta, aqui feita, de categorização em subáreas de Moda e Sustentabilidade, como já apresentada, exibida na Tabela 3.

Tabela 3: Incidência de artigos sobre Sustentabilidade no Colóquio de Moda, dividido por categorias

\begin{tabular}{|c|c|c|c|c|c|c|}
\hline \multirow[b]{2}{*}{$\begin{array}{c}\text { Edição Ano - } \\
\text { Cidade }\end{array}$} & \multirow{2}{*}{$\begin{array}{c}\text { Número de } \\
\text { Artigos sobre } \\
\text { Sustentabili- } \\
\text { dade }\end{array}$} & \multicolumn{5}{|c|}{ Categorias da Moda e Sustentabilidade $-\mathrm{N}^{\circ}$ de Artigos } \\
\hline & & $\begin{array}{l}\text { Matéria- } \\
\text { Prima }\end{array}$ & Processos & Consumo & $\begin{array}{l}\text { Fim de } \\
\text { Ciclo de } \\
\text { Vida }\end{array}$ & $\begin{array}{c}\text { Transpa- } \\
\text { rência }\end{array}$ \\
\hline $\begin{array}{l}\text { 2005- Ribeirão } \\
\text { Preto/SP }\end{array}$ & 2 & 1 & - & - & - & - \\
\hline $\begin{array}{l}2006- \\
\text { Salvador/BA }\end{array}$ & 9 & 1 & 3 & 3 & 1 & - \\
\hline $\begin{array}{l}2007-\text { Belo } \\
\text { Horizonte/MG }\end{array}$ & 7 & - & 3 & 2 & 1 & - \\
\hline $\begin{array}{l}2008 \text { - Novo } \\
\text { Hamburgo/RS }\end{array}$ & 15 & 2 & 3 & 4 & 3 & - \\
\hline
\end{tabular}

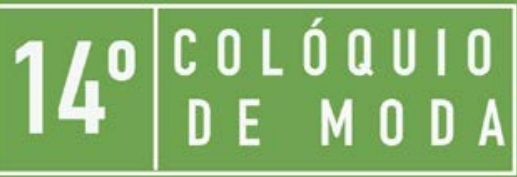

\section{abepem}




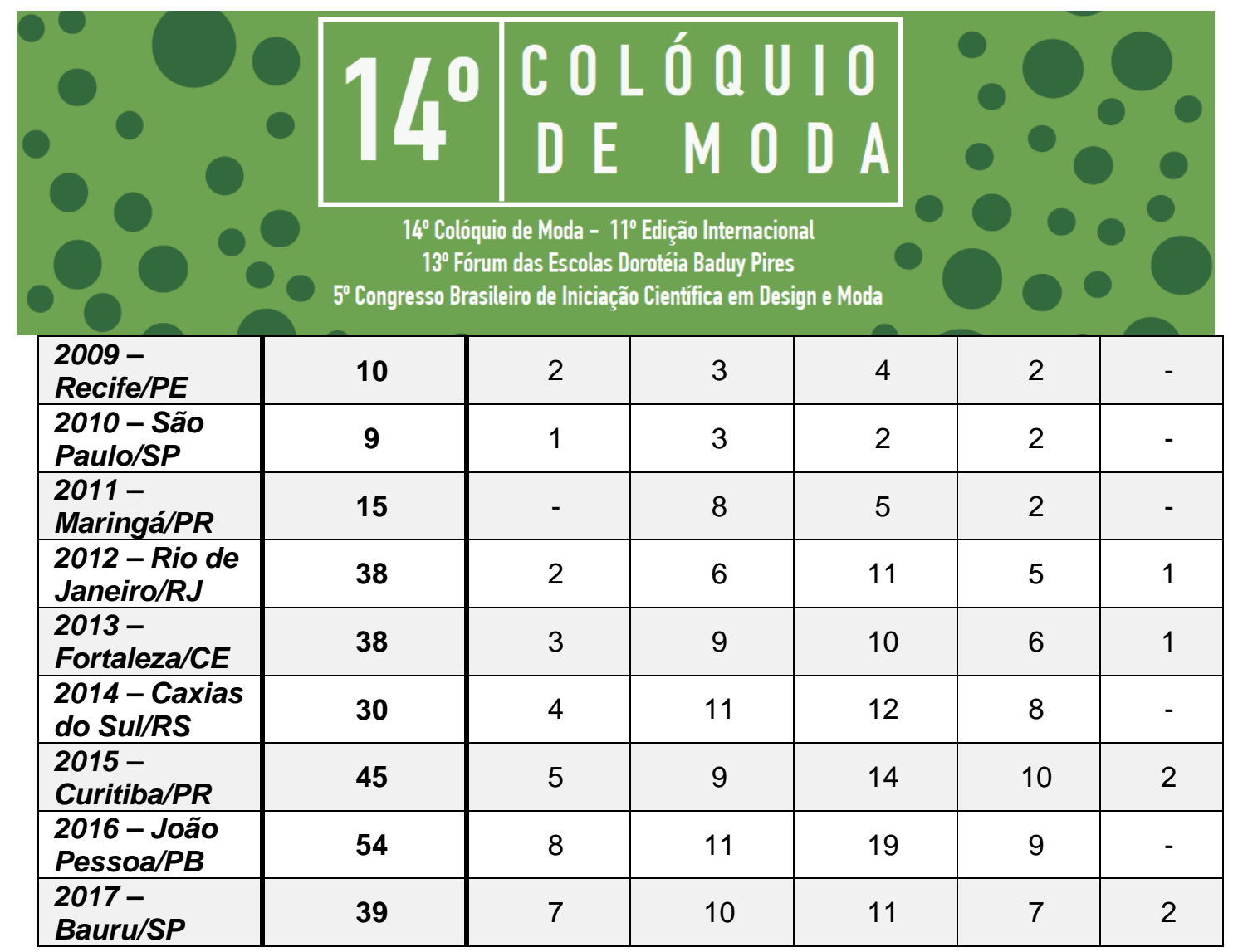

Fonte: Criada pelos autores deste artigo, baseado nos anais dos Colóquios de Moda (2005-2017)

É importante memorar que na distribuição realizada dos artigos nas categorias propostas deu-se pela análise tanto das palavras-chaves, dos resumos, quanto do conteúdo dos mesmos. A soma dos artigos de cada categorias nem sempre resultou no mesmo número apresentado na coluna "Número de artigos apresentados sobre Sustentabilidade", uma vez que muitos artigos não abordam exclusivamente uma das categorias. Existem ainda artigos que não retratam nenhuma das categorias, mas o aspecto teórico-crítico da Sustentabilidade na relação com a Moda, e vice versa. Motivos pelos quais a soma pode ser superior ou inferior ao número total de artigos sobre a temática, em cada edição.

\section{Análise de Dados}

Partindo das apresentações quantitativas, faz-se necessária uma ponderação analítica, como parte qualitativa. Ademais, lembra-se que mesmo com o estabelecimento do GT Moda e Sustentabilidade, as pesquisas apresentadas no 


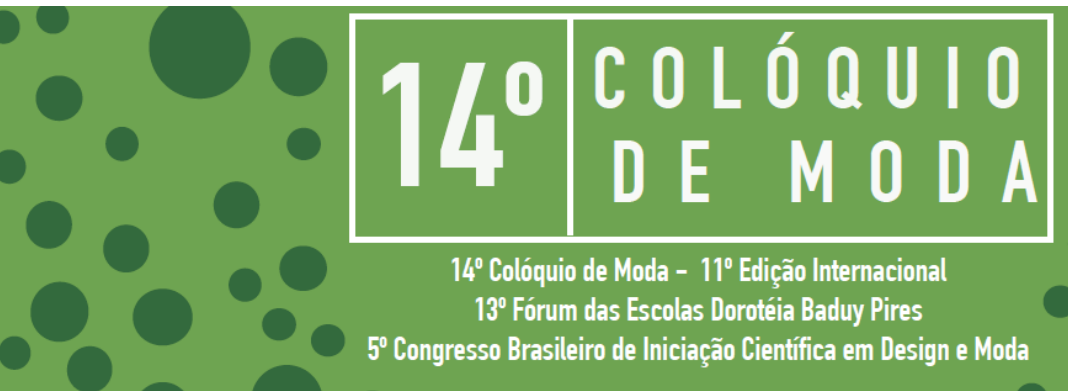

colóquio sobre essa temática extrapolam a participação à outros GTs, com destaque para o de Consumo, mas aparecendo, por vezes, ainda, no de Educação, no de Mídia, no de Processos Produtivos, no de Estética e Ética, no de Estilo de Vida, no de Tecnologia e no de Modelagem.

Notadamente, a categoria "Transparência" apresenta quantitativo significativamente menor que as demais. Este fato pode estar vinculado à complexidade em se afirmar a verossimilhança dos produtos e materiais no contexto de serem efetivamente sustentáveis. E, de um modo geral, não parece ser algo contemplado como temática nas graduações e pós-graduações em Moda no Brasil. Apenas na recorrência a selos e certificações internacionais pode-se demonstrar transparência e idoneidade da Sustentabilidade num produto, projeto ou material, configurando a complexidade desta temática. Em nenhum dos trabalhos publicados pode-se verificar o debate aprofundado sobre estes organismos avalistas, mas debates em torno da questão.

Já o critério "Fim de Ciclo de Vida do Produto" verifica-se fartura de propostas e projetos envolvidos com a Reciclagem e seus variantes (Reuso, Redesign, Upcycling, etc.), em especial ao resíduo têxtil de pós-consumo. Os âmbitos ambiental e ecológico são tônicas permanentemente constantes na maioria das produções deste segmento. Especificamente, esta categoria é a que possui artigos com maior número de incidência, conjuntamente, com outras categorias, com relatos também em "Matéria-Prima" (em materiais como o PET reciclado), "Consumo" (como na customização de peças de segunda-mão) e "Processos" (como procedimentos e metodologias para reutilização de descartes).

No aspecto "Consumo" é possível visualizar o maior número de publicações gerais, sendo o primeiro lugar em 9 edições (nas seis últimas, 


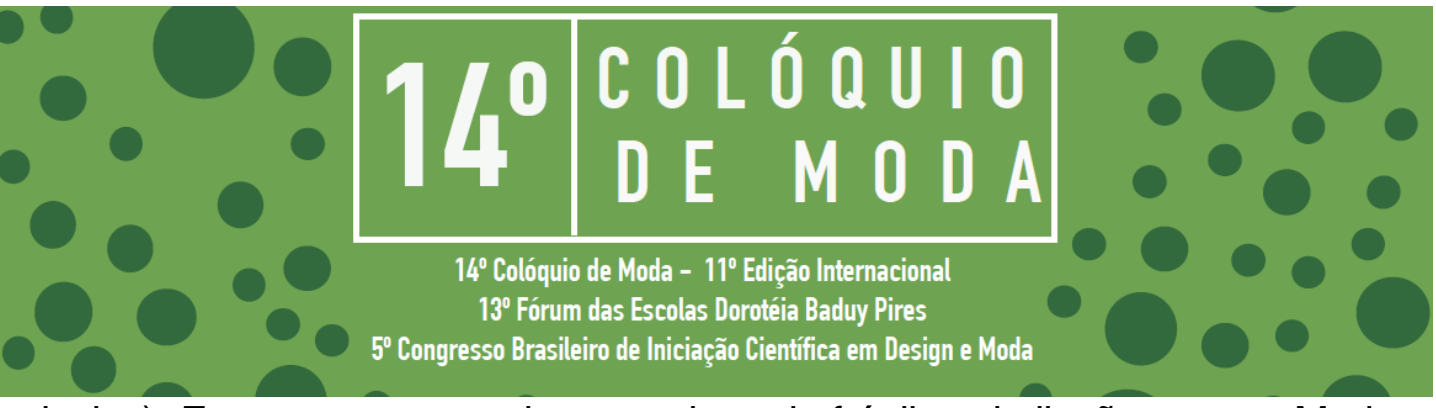

inclusive). Este segmento pode ser o de mais frágil assimilação entre a Moda e a Sustentabilidade, uma vez que por essência, a Moda propõe um consumo constante, característico da sociedade ocidental, moderna e capitalista (LIPOVETSKY, 2009), enquanto que o consumo deve ser relativizado, conscientizado e responsável no viés da sustentabilidade (BERLIM, 2012). Projetos coletivos/ de coletividade e de compartilhamento são os maiores representantes nos artigos deste segmento, especialmente, nos últimos 5 anos e "Moda ética" é um tema comumente abordado.

Por outro lado, o segmento "Processos" também demonstra relevância quantitativa, sendo o segundo em termos gerais. Esse numeroso valor apresentado é perceptível uma vez que a complexa cadeia produtiva da indústria têxtil e de confecção engloba diversas etapas e distintos atores da pré-produção à distribuição, ou até mesmo o descarte, se entendido o consumidor como parte envolvida no processo geral (FLETCHER, 2011). Processos manuais (ora artesanato) e a valorização da mão de obra humana são pertinências mais recorrentes. Merece destaque, ainda, os processos com uso racionalizado de recursos naturais, em preferência aos sintéticos. Pode-se dizer que esta categoria é intermediadora entre as demais, podendo potencializar ou inferiorizar a sustentabilidade no aspecto geral dos projetos e produtos a depender dos demais. Pois, de que adianta processos sustentáveis, ecologicamente corretos e socialmente justos, se feitos em matéria-prima agressora ao meio ambiente ou com alto índice de descartes poluentes? Ou, que não estimule o consumo racionalizado dos (possíveis) usuários? Ou, ainda, que não tenha potencial de reciclabilidade, gerando descartes impróprios à reutilização? 


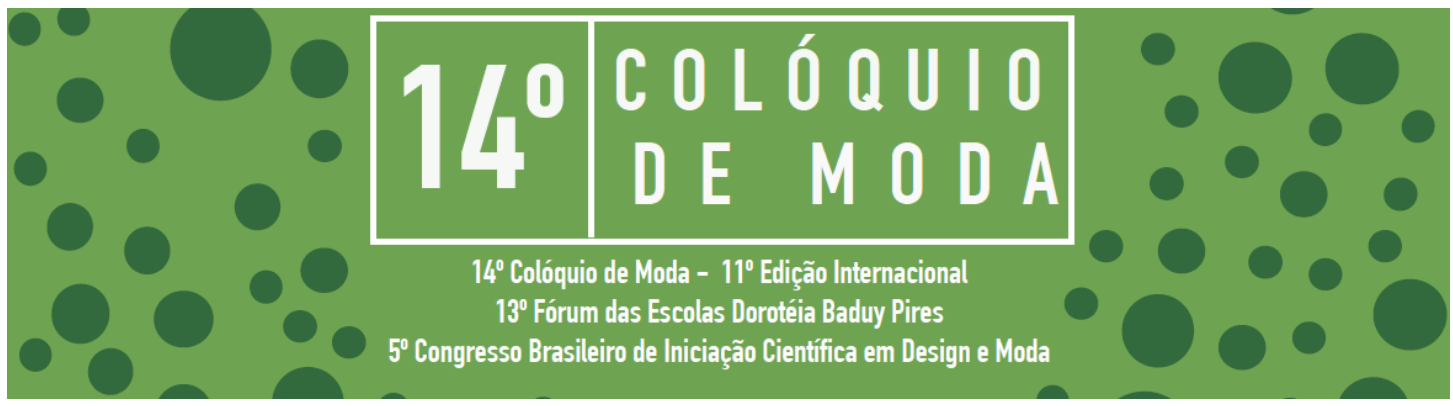

Enfim, na linha "Matéria-prima" os materiais têxteis são majoritários, entretanto existem investigações apresentadas, também, sobre materiais não têxteis, como substitutivos ao couro animal, ou mesmo, propostas que sugerem insumos não tradicionais. Nesta sessão, verifica-se que a Tecnologia é um aliado de primeira instância aos estudos apresentados de sustentabilidade. Mesmo tendo produção numérica inferior à três outras categorias, esta deve ser observada minuciosamente uma vez que é estabelecida como etapa anterior aos processos produtivos da indústria de confecção, tornando (potencialmente) mais sustentável os processos e o produto em si, como nos lembra Thompson e Thompson (2013). Os termos "orgânico" e "reciclado" são correntemente retratados nesta sessão.

\section{Considerações Finais e Estudos Futuros}

Deste modo, com os apontamentos elencados anteriormente, pode-se perceber que a Moda e a Sustentabilidade, em conjugado, estão, paulatinamente, conseguindo criar interações interessantes, a partir da análise de estudos, projetos, marcas e designers apresentados nos Colóquios de Moda. Porém, não é ainda possível se afirmar que se trata de uma área de pesquisa/estudos consolidada globalmente. Mas é assertivo e seguro dizer e reconhecer o status quo que têm se notabilizado, como aqui demonstrado, quantitativa e qualitativamente, no recorte de um importante congresso para o segmento de Moda.

A aglutinação, proposta de cinco categorias, atende aos anseios apontados nos conceitos retratados pelos renomados autores do segmento. E, por sua vez, os autores dos artigos do Colóquio assimilam-se à uma(s) ou outra(s) categorias, de acordo com suas áreas de atuação e aspirações para investigações, 


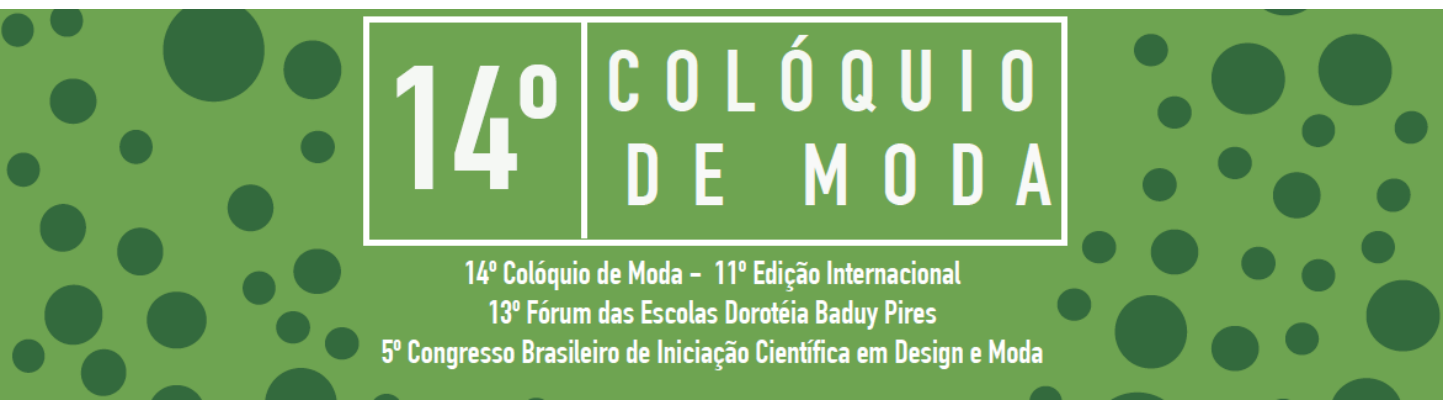

na maioria das vezes, ensejando construir contributos às preocupações ambientais e ecológicas.

Diante da apresentação numérica, poderia ser espontâneo afirmar que a categoria "Transparência", que relata sobre a idoneidade do sustentável, possui ampla e vasta área a ser explorada e investigada. Ou, também sob a mesma argumentação, que muito já fora explorado sobre "Consumo" e "Processos". No entanto, é preciso se ponderar a analise, equilibrando os quantitativos com o qualitativo. De fato, lembra-se que, por se tratar de recente assimilação a dialógica de Moda e Sustentabilidade, revelando a não existência de conceitos acabados e definitivos, em plenitude e inquestionáveis. Esta é, ainda, uma nova fronteira de conhecimento e debate, quiçá, incipiente, mesmo que crescente. Em fato, concluise que nenhuma das categorias está completamente preenchida e/ou sem lacunas.

Mesmo que com menor volume, o segmento "Transparência" ainda precisa de ser mais debatido e investigado, pois muitos dos autores não se familiarizaram com a temática, compreendendo, por exemplo, sobre Fair Trade e selo ISO 14000 (selo do International Organization for Standardization). Não há, ainda, projetos, marcas e/ou produtos, abordados nas pesquisas, que compreendam a profundidade e importância da certificação. O que acredita-se que pode deixar, ainda, espaço no mercado de consumo para Greenwashes (MANZINI e VEZZOLI, 2011).

Destaca-se como importante e significativo a necessidade de se explorar no ramo de "Matérias-Primas", investigando aspectos como: a potencialidade orgânica de fibras naturais (como algodão e linho); a não afetação ao ciclo de vida natural de outros organismos (como a seda silvestre); a diminuição de uso de água
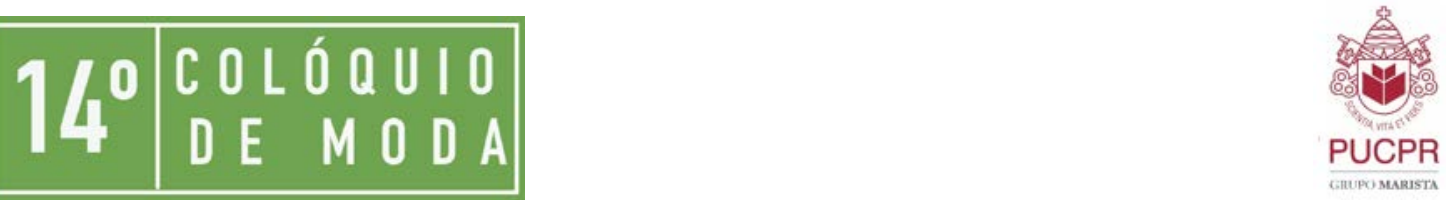

\section{abepem}




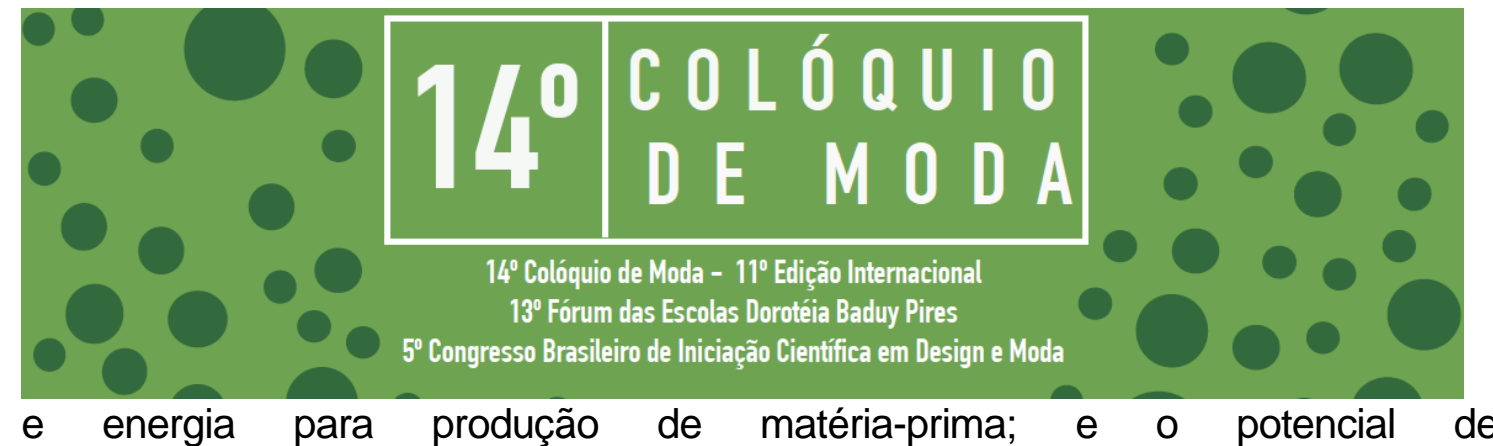

reutilização/reciclabilidade da fibra para se refazer, quando descartada. Outra saliência, contudo, pode estar em pesquisas para desenvolvimento de materiais equivalentes ao couro, seja da reciclagem de outras fibras, como já tem aparecido, ou reciclagem dos próprios resíduos/rejeitos couro, como material, ainda em hiato. Faz-se uma importante ressalva que ainda paira certa inadequação do uso do termo "reciclagem" (e termos variantes). Nesse sentido é fundamental lembrar Leonas (2017) que distingue, categoricamente, reciclagem e reuso para o têxtil (e, por consequência, para o vestuário), havendo apresentado as categorias "préconsumo", "pós-industrial" e "pós-consumo" como tipos de resíduos a serem reciclados/reusados.

A maior parte dos autores de Moda e Sustentabilidade consultados (BERLIM, 2012; LEE, 2009; FLETCHER, 2011; SALCEDO, 2014; STYLES, 2014), e em especial Thompson e Thompson (2013), argumentam da importância de se pesquisar e desenvolver materiais de insumo mais sustentáveis, potencializando o restante da cadeia de produção, elegendo, assim, a matéria-prima, como a mais importante para este segmento de estudos - Moda e Sustentabilidade.

Portanto, o histórico de publicações do Colóquio de Moda demonstra que, aos poucos, o tema Moda e Sustentabilidade foi sendo inserido nos artigos até se tornar um GT específico, que é considerado, hoje, de significativa importância. Mesmo com seu merecimento na presença de artigos, muito ainda há de ser explorado futuramente, em pesquisas de Moda e Sustentabilidade, em todas as cinco categorias, aqui elencadas. Faz-se necessário, apenas, compreender criticamente que, a partir de então, precisa-se estabelecer fundamentações teóricas melhor embasadas a fim de contribuir qualitativamente no debate. 


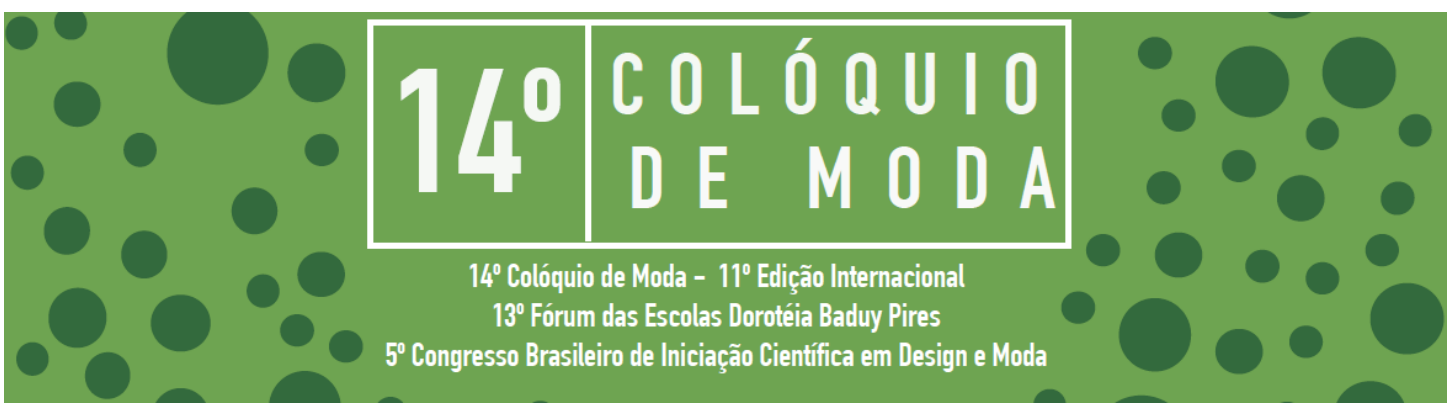

Diferentemente de uma tendência de Moda, a abordagem de/em

Sustentabilidade faz-se superior, não tendo esperado um momento de queda e possível esquecimento até seu "ressurgimento". Trata-se de um novo modelo de estado de espírito e pensamento crítico-reflexivo, a ser incluído nas práticas do designer e dos projetos e produtos de moda. Como nos lembra Boff (2012), o futuro pela sustentabilidade é um caminho sem voltas e irrevogável.

\section{Referências}

BERLIM, L. Moda e Sustentabilidade: Uma reflexão necessária. São Paulo: Estação das Letras e Cores, 2012.

BOFF, L. Sustentabilidade: o que é - o que não é. Petrópolis: Editora Vozes, 2012.

BROWN, S. Eco Fashion. London: Laurence King Publishin Ltd, 2010.

CASTILHO, K; MATTOS, M. F. (orgs.) Colóquio de Moda: 10 Anos. São Paulo: Estação das Letras e Cores, 2015.

COLÓQUIO de Moda - Anais. 2018. Disponível em: <http://www.coloquiomoda.com.br/anais/> Acesso em: 20 mar. 2018.

FLETCHER, K. Moda \& Sustentabilidade: design para mudança. São Paulo: Senac São Paulo, 2011.

GWILT, A. Moda sustentável: um guia prático. São Paulo: Gustavo Gili, 2014.

LEE, M. Eco Chic: o guia da moda ética para a consumidora consciente. São Paulo: Larousse do Brasil, 2009.

LEONAS, K. The use of recycled fibers in Fashion and Home products. In: Textiles and Clothing Sustainability, Springer, V. 7 (2017), p 55-77, 2017.
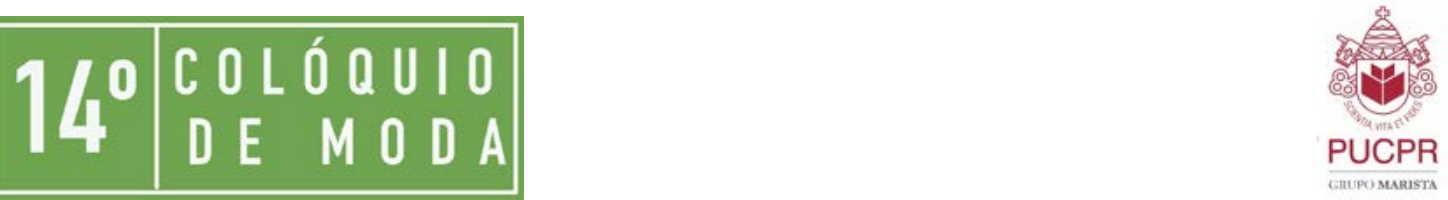

\section{abepem}




\section{COLÓQUIO DE MODA \\ $14^{\circ}$ Colóquio de Moda - $11^{\circ}$ Edição Internacional \\ $13^{\circ}$ Fórum das Escolas Dorotéia Baduy Pires \\ $5^{0}$ Congresso Brasileiro de Iniciação Cientifica em Design e Moda}

LIPOVETSKY, G. O império do efêmero: a moda e seu destino nas sociedades modernas. Edição de bolso. São Paulo: Companhia das Letras, 2009.

MANZINI, E; VEZZOLI, C. O Desenvolvimento de Produtos Sustentáveis: Os requisitos ambientais dos produtos industriais. São Paulo: Ed. EDUSP, 2011.

MIRANDA, A. P. 10 Anos de Colóquio de Moda. In: CASTILHO, K.; MATTOS, M. F. (orgs.) Colóquio de Moda: 10 Anos. São Paulo: Estação das Letras e Cores, 2015, p. 56-61.

PUPPIM, R.; BEDUSCHI, D. P. Epistemologia do Eco Fashion: Contributos à prática do Design de Moda e Sustentabilidade. In: Encontro de Sustentabilidade em Projeto (ENSUS), UFSC, VI, 2018, Florianópolis/SC. Anais (on-line). Disponível em: < http://ensus2018.paginas.ufsc.br/anais/> Acesso em: 01 jul. 2018.

QUEIROZ, L. L. Utopia da sustentabilidade e transgressões no design. Rio de Janeiro: Editora 7 Letras, 2014.

SACHS, I. Caminhos para o desenvolvimento sustentável. Rio de Janeiro: Garamond, 2009.

SALCEDO, E. Moda ética para um futuro sustentável. São Paulo: Gustavo Gili, 2014.

SCHULTE, N. K. Reflexões sobre moda ética. Florianópolis: Editora UDESC, 2015.

SILVA, C. V.; GIULIANO, C. P. Sustentabilidade e Moda: um estudo bibliométrico dos Anais do colóquio de moda. In: Revista Conhecimento Online. Ano 9, v. 2 (Jul/Dez 2017), p 92-104, 2017.

STYLES, R. Ecologist guide to Fashion. London: Thames \& Hudson Pub., 2014.

THOMPSON, R.; THOMPSON, M. The Manufacturing guides: Sustainable materials, processes and production. London: Thames \& Hudson, 2013.

VEIGA, J. Sustentabilidade: a legitimação de um novo valor. São Paulo: Senac São Paulo, 2010.
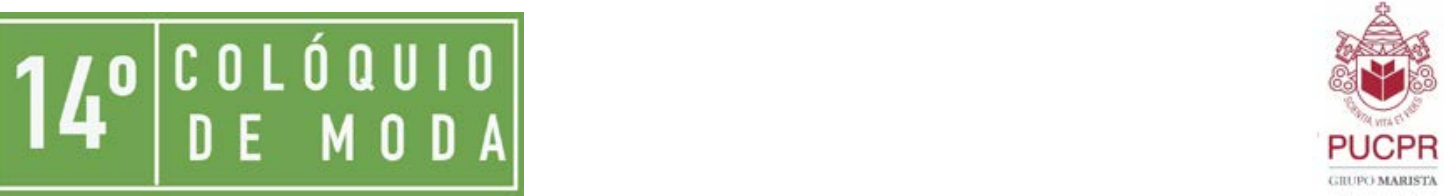

\section{abepem}

